\title{
Missões Batistas em Angola e Moçambique no período de descolonização: apontamentos para uma discussão do discurso da revista $O$ Campo é o Mundo.
}

\author{
Harley Abrantes Moreira ${ }^{1}$
}

\section{RESUMO}

Este artigo procura discutir as aspectos das relações culturais entre missionários batistas brasileiros e africanos angolanos e moçambicanos no início da década de setenta do século XX. O material analisado consiste em fragmentos da revista missionária $O$ Campo é o Mundo, produzida pela Junta de Missões Mundiais da Igreja Batista. Destacam-se neste texto, as ideias de representação e alteridades em Roger Chartier, Tzevetan Todorov e Stuart Hall respectivamente. Além de noções da análise do discurso a partir das autoras Enni Orlandi e Helena Nagamini Brandão. Como problema central, apontamos o protagonismo do sujeito histórico africano.

Palavras chave: Missões-alteridades-África.

\begin{abstract}
This paper discusses the aspects of cultural relations between Brazilian Baptist missionaries and African Angolans and Mozambicans in the early seventies of the twentieth century. The material analyzed consists of fragments of the missionary magazine The Field is the World, produced by the Foreign Mission Board of the Baptist Church. Also in the text, the ideas of representation and alterity in Roger Chartier, Tzevetan Todorov and Stuart Hall respectively. Beyond notions of discourse analysis from the authors Enni Orlandi and Helena Nagamini Brandão. As the central problem, we highlight the role of the African historical subject.
\end{abstract}

Keywords: Missions-Africa-otherness.

O Fenômeno das missões religiosas na África alterou sobremaneira as dinâmicas culturais e políticas do continente. A partir das possibilidades de "mediação missionária" podemos pensar que os complexos aspetos da interação cultural, linguística, cosmogônica e política da relação entre missionários ocidentais protestantes - e as populações africanas foram fundamentais para a compreensão das transformações do século XX na África.

Nesse texto, tentaremos discutir o discurso da Igreja Batista, através de suas agências missionárias, sobre as regiões africanas de colonização portuguesa, seus

\footnotetext{
${ }^{1}$ Professor efetivo do curso de História da Universidade Estadual de Pernambuco, unidade Petrolina. Possui mestrado em História pela UFRN (2009), graduação em História pela Universidade Federal do Ceará (2000) e Bacharelado em Teologia pelo Seminário Teológico Batista do Norte do Brasil (2005). Desenvolve pesquisas nos seguintes temas: Alteridades religiosas e História das Religiões; Relações entre sertões e litoral no início do século XX.
} 
contextos socioculturais, suas religiões tradicionais e o povo africano, concebido como um alvo missionário. Para isso, serão analisados artigos da revista $O$ Campo é o Mundo, produzida pela Junta de Missões Estrangeiras da Convenção Batista Brasileira, durante o período de descolonização, com ênfase em duas colônias: Moçambique e Angola. Importa aqui, pensar o sentido que se construía para o continente através deste discurso religioso da revista que, em suas páginas, construía um outro, pagão-africano, em uma perspectiva que será analisada à luz das observações teóricas de Tzevetan Todorov sobre as alteridades e de alguns conceitos da análise do discurso, em especial a noção de interlocução que, segundo Helena Nagamine Brandão, consiste no processo de interação entre indivíduos através da linguagem verbal e não verbal (BRANDÃO, 2010). Iniciaremos com alguns apontamentos acerca dos batistas, posteriormente, passaremos à discussão de matérias do periódico relevantes para pensar o problema das alteridades e dos colonialismos culturais como trama discursiva dessas fontes.

\section{OS BATISTAS NO BRASIL E SUAS AGÊNCIAS MISSIONÁRIAS}

A denominação batista inicia suas missões, no Brasil, no final do século XIX e, embora os batistas se espalhassem por diversos países europeus e pudessem se caracterizar por certa diversidade, fruto de princípios como a democracia e a autonomia de suas igrejas, o movimento missionário que migrou para o Brasil foi de procedência norte-americana (SILVA, 2003) e, por isso, pode-se afirmar que suas características eram bastante específicas. Nos Estados Unidos, o protestantismo chegara da Inglaterra através do conhecido fluxo de imigração do século XVII, deslocando daquele país, puritanos calvinistas que, fugindo de perseguições religiosas, tinham em alta conta a ideia de que formavam um grupo escolhido por Deus para construírem nova vida e nova sociedade de "eleitos" em uma espécie de nova Canaã. Segundo Leandro Karnal, a ideia de nação eleita e escolhida por Deus é, ainda hoje, uma das marcas culturais mais fortes dos Estados Unidos, constituindo-se em um dos elementos formadores do seu mito de fundação (KARNAL, 2010).

A imagem da nova Canaã, segundo Elizete da Silva², voltará a se repetir quando dos movimentos missionários estadunidenses que chegaram ao Brasil na

\footnotetext{
${ }^{2}$ SILVA, Elizete da. Visões Protestantes Sobre a Escravidão. Revista de Estudos da religião, nº 1, 2003, PP.1-26.
} 
segunda metade do XIX. Ocorre que, naquele período, os Estados Unidos e os batistas daquele país se dividiam em dois grandes blocos em função da guerra de secessão (1861-1865) que opôs, de um lado, nortistas liberais, defensores da livre concorrência e de uma ética trabalhista protestante e, de outro, sulistas escravagistas que possuíam a maior convenção batista dos Estados Unidos, justamente aquela que estabeleceu a Denominação Batista em solo brasileiro. Com suas famílias e derrotados na guerra civil, tais missionários teriam migrado no intuito de reconstruir suas propriedades, realizando nessa nova terra um modo de vida semelhante ao de seu lugar de origem, o sul escravista e decadente daquela nação.

Os batistas que chegavam ao Brasil em fins do século XIX eram os antigos escravagistas ruralistas do Sul dos Estados Unidos e seu perfil teológico pode ser compreendido dentro desses parâmetros. A ênfase missionária era uma das principais características desses protestantes e não tardou para que tais grupos organizassem suas instituições missionárias brasileiras, destacando-se a Junta de Missões Nacionais, criada em 1907, já na primeira assembleia da Convenção Batista Brasileira, da qual resultou também $^{3}$ a Junta de Missões Estrangeiras (JME), hoje, Junta de Missões Mundiais (JMM).

O intuito da JME era promover a expansão batista através da evangelização de povos e países espalhados pelo globo. O primeiro a receber missionários batistas brasileiros enviados pela Junta foi Portugal que, em 1911, recebeu o Pr. João Jorge de Oliveira. $^{4}$

\section{A REVISTA $O$ CAMPO É $O$ MUNDO: COLONIALISMOS E ALTERIDADES}

De acordo com informações divulgadas no site da Junta de Missões Mundiais, a revista $O$ Campo é o Mundo foi criada a partir de 1955, quando da administração de Alcides Telles de Almeida, então diretor executivo dessa agência missionária. ${ }^{5} \mathrm{O}$ periódico tinha por objetivo divulgar notícias sobre as missões batistas brasileiras em

\footnotetext{
${ }^{3}$ (http://www.missoesnacionais.org.br/publicacao.asp?codCanal=7)

${ }^{4}$ (Disponível:http://www.jmm.org.br/index.php?option=com_content\&task=view\&id=1 24\&Itemid=147)

${ }^{5}$ Ibdem, ibdi
} 
outros países através de cartas e relatos dos missionários, informações sobre os contextos locais para onde eram enviados, notas sobre países que almejava atingir através das missões, além da divulgação de campanhas missionárias e apelos que visavam a conscientização dos fiéis quanto a necessidade de investimentos.

Durante as décadas de sessenta e setenta do século XX a revista foi publicada trimestralmente. Através desse material, é possível discutir o discurso dos batistas brasileiros que almejavam atingir todas as regiões do mundo e, em especial, o continente africano que, naquele momento, representava um dos principais focos de atuação missionária dessa denominação.

Durante o período de descolonização da África lusófona, a presença de missionários batistas brasileiros se intensificava em colônias como Moçambique e Angola. Segundo relação da Junta de Missões Estrangeiras, relatada pela referida revista, em 1974, já eram oito:

Em Moçambique: Pastor José Nite Pinheiro e Cilcéia Cunha Pinheiro; Valnice Milhomens Coelho; Albertina Ramos da Silva; Lourenço Marques e Maria Ivonete da Costa. Em Angola: Pastor Levy Barbosa da Silva; Elizabeth Barbosa da Silva e Elnice de Brito. (REDAÇÃO, 1974, p. 27).

Outros missionários batistas, enviados por agências missionárias internacionais de países como Estados Unidos, Canadá ou Austrália já se faziam presentes nestes países, décadas antes da chegada dos brasileiros que, de certa forma, teriam sido beneficiados por seus trabalhos. Em outra matéria sobre um artigo escrito por um desses missionários ainda na década de cinquenta, a redação da Revista afirmava que

O Pastor A. Antônio Bornes, obreiro da Baptist Missionary Society, desde 1959, foi missionário em Angola por alguns anos [...] Seu artigo divide-se em duas partes: a primeira refere-se às atividades missionárias por ele realizadas e oque presenciou até 1961; a segunda parte é um breve relato no que respeita a situação da evangelização. As informações que seguem precisam ser lidas com oração, de joelhos, para que Deus tome uma providência e abra as portas dos céus em favor daquelas almas sofredoras. [...] Desde 1948, 
aprofundou-se a penetração portuguesa pelo interior do continente angolano com forte presença católica. Questões políticas que as vezes envolvem nossos missionários sem que eles queiram[...] As igrejas batistas cresceram animadoramente nos últimos vinte anos. (REDAÇÃO. 1966, p. 4 e 5)

Segundo as informações relatadas, Angola já era campo de uma variedade de juntas missionárias evangélicas que cooperavam com a Aliança evangélica de Angola, com sede na capital Luanda, para "poder atender às necessidades do país" (Ibdem, Ibdi) e, uma vez que nossa problematização central diz respeito à discussão das alteridades, de como se comportar em relação a outrem (TODOROV, 1996), ou de "como o colonizador produz o colonizado e vice-versa" (HALL, 2002, p.31), é importante notar, em trechos como este, a construção histórica e discursiva do outro e de sua diferença, muitas vezes marcada pelo sinal do sofrimento, da carência e, consequentemente, da vitimização e inferioridade. Na concepção do missionário, os povos africanos são "almas sofredoras".

Nesse sentido, aponta-se a necessidade de compreender determinadas construções de sentidos a partir da formação discursiva dentro da qual se alojava a revista, ou seja, compreendendo a impossibilidade de qualquer "sentido a priori" (ORLANDI, 2003, p.23), uma vez que este é construído no tempo histórico e nos "processos de interlocução" (BRANDÃO, 2001, p.108), é necessário indagar pela consideração do africano como interlocutor do missionário nos processos de construção de sentidos para a África. Dito de outra forma, em que medida o discurso da revista revela ou torna invisível os africanos.

No mesmo editorial sobre as missões em continente africano, a redação da revista continua destacando o depoimento cedido pelo pastor Antônio Boorne que passa a revelar diversas impressões e generalizações importantes para discutirmos o discurso missionário batista sobre a África Lusófona e o sentido construído "para os" africanos:

Talvez seja difícil imaginar o ambiente psicológico da mente de uma pessoa criada no puro fetichismo, que exerce influência tão profunda sobre sua mente, que chega a viver assombrada pelo paganismo. Muitos apesar de crentes. Por isso a igreja se torna tão exigente para o 
ingresso de novos membros. O meio ambiente também serve de base para justificar a disciplina da igreja. As orgias noturnas com os batuques que fazem vibrar a solitária noite, os tambores, a potentíssima bebida alcoólica e toda espécie de feitiçaria e imoralidade que se misturam. Essas coisas, como não poderia deixar de ser, são proibidas aos crentes.

As bebidas alcoólicas constituem uma tentação muito forte para alguns. As danças rítmicas, sugestivas, temperadas com uma dose liberal do álcool, levam o africano que a elas se entrega a um arrebatamento que só se pode chamar de satânico. Os problemas de casamento não são menos melindrosos, a poligamia é tradicional. Ainda é comum homens com cinco ou seis mulheres e uma dezena de filhos.

A cultura do povo leva a algumas experiências bastante engraçadas. Por exemplo, o dinheiro quase nunca é usado pelo angolano, por isso, o povo mal podia contribuir. Via de regra, ao ser recolhida a oferta, o cesto rústico corria o salão e os congregados e o povo colocavam batata doce, ovos, tomate, mandioca, galinhas e umas poucas moedas, depois o missionário comprava ou vendia essas coisas para que pudessem constar como entradas em centavos e escudos para os cofres da igreja. (1966, nº4. p.7).

O texto transcrito é particularmente rico a quem deseja perceber a compreensão que se tinha do africano por parte dos missionários, quais as variações da distância entre estes e os outros. Ao confessar a dificuldade de imaginar o ambiente psicológico dos angolanos, o pastor revela, também, não só o nível de estranhamento cultural como um determinado desinteresse por qualquer tipo de diálogo com aquela cultura e mesmo a incapacidade de realiza-lo, afinal, sendo "difícil imaginar" as religiões locais, afere-se que, para aquele obreiro, seria impossível dialogar com elas.

O pastor Antônio Boorne era, então, um missionário da JMM e a sua compreensão das práticas culturais africanas, de certa forma, se condicionavam à agência missionária com a qual mantinha uma relação, imagina-se, de fé e de trabalho. Seu depoimento tinha por destino centenas de igrejas batistas brasileiras, as quais colaboravam, financeiramente e através de suas orações, com a sua atividade evangelizadora. O sujeito histórico em questão era, portanto, produtor de um relato que precisava atingir essas comunidades no sentido de sensibilizá-las para a obra das missões e de convencê-las quanto à importância de sua fidelidade contributiva. A 
construção discursiva de um povo africano pagão, lascivo, alcoólatra e polígamo parecia ser, dessa forma, uma importante estratégia de sensibilização.

O termo pagão, ao que sugere Mário Curtis em seus estudos sobre a África anterior aos descobrimentos, já era utilizado à época, de forma genérica, para referir-se ao notável pluralismo religioso do continente e às diferentes características das distintas religiões africanas (GIORDANI, 2010), uma das quais, a crença nos poderes mágicos de determinados objetos, essa prática cultural era apontada pelo pastor como alvo de seu combate: o fetichismo.

Para o missionário batista, tais religiosidades locais representavam uma assombração para a vida de seus adeptos. O reconhecimento da existência de pessoas que conviviam harmoniosamente com sua própria religião não é mencionado pelo pastor que parece não admitir essa possibilidade quando denomina de satânicos os rituais que prefere resumir como um conjunto de danças sensuais executadas por pessoas alcoolizadas que, segundo o relato, possuiriam uma relação tensa com sua própria religião.

A ênfase nos elementos ritualísticos que a redação da revista denomina de “orgias", "batuques", "feitiçaria" e "imoralidade" são pistas importantes para prosseguir interrogando o sentido desses termos nas comunidades batistas brasileiras, leitoras do periódico e destinatárias do relato missionário. A opção pela utilização destes termos, os quais passam a representar a cultura religiosa tradicional africana apontam para a rejeição e inferiorização do outro, na medida em que indicam o não reconhecimento de determinadas práticas como traços de uma outra religião e "exprimem a maneira pela qual uma comunidade produz sentido, vive e pensa sua relação com o mundo" (CHARTIER, 1999, p. 8-9).

Diversos outros elementos envolvendo problemas de alteridades podem ser discutidos a partir do trecho transcrito, a atitude do missionário de "rir" do outro por este outro não utilizar dinheiro é uma delas. Na experiência religiosa e de vida do pastor o habitual era que, ao chegar em diferentes campos missionários, a igreja estabelecesse seus hábitos, seus ritmos, seus instrumentos musicais, sua liturgia e sua cultura.

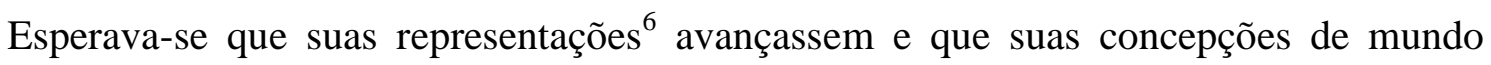

\footnotetext{
${ }^{6}$ Segundo Roger Chartier, as representações dizem respeito às classificações, divisões e delimitações que organizam o mundo social como categorias fundamentais da percepção e de apreciação do real. Variáveis,
} 
convertessem a cultura africana dentro de um movimento semelhante às afirmações de Roger Chartier quando este explica que

\begin{abstract}
As representações aspiram à universalidade, mas são sempre determinadas pelos interesses dos grupos que as forjam. O poder e a dominação estão sempre presentes. As representações não são discursos neutros: produzem estratégias e práticas tendentes a impor uma autoridade, uma deferência, e mesmo a legitimar escolhas. Ora, é certo que elas colocam-se no campo da concorrência e da luta. Nas lutas de representações tenta-se impor a outro ou ao mesmo grupo sua concepção de mundo social (CHARTIER, 1990, p. 17).
\end{abstract}

Deparar-se com uma cultura local na qual o uso do dinheiro concorria com o escambo e não era comum a todas as pessoas, era uma novidade surpreendente, obrigava os missionários a improvisar novas formas litúrgicas e, no momento em que o missionário revela considerar engraçada tal situação, parece-nos que não lhe ocorreu que o sistema monetário era um valor inerente à sua cultura moderna, ocidental e capitalista. Causava-lhe espanto, portanto, saber que seus valores não eram universais.

Por outro lado, é possível achar graça do outro quando esse outro me é inferior ou inofensivo, quando suas representações não tendem a impor uma autoridade e uma concepção específica de mundo social. Se o outro é igual, temos aí uma espécie de ameaça e o inusitado perde a graça mediante o poder deste estranho que me é equivalente.

\title{
Segundo Tzevetan Todorov,
}

É preciso distinguir entre pelo menos três eixos, nos quais pode ser situada a problemática da alteridade. Primeiramente um julgamento de valor, (um plano axiológico): o outro é bom ou mau, gosto dele ou não gosto dele, ou, como se dizia na época, me é igual ou me é inferior (pois, evidentemente, na maior parte do tempo, sou bom e tenho autoestima...). Há, em segundo lugar, a ação de aproximação ou de 
distanciamento em relação ao outro (um plano praxiológico): adoto os valores do outro, identifico-me a ele; ou então, assimilo o outro, impondo-lhe minha própria imagem; entre a submissão ao outro e a submissão do outro, há ainda um terceiro termo, que é a neutralidade ou indiferença. Em terceiro lugar, conheço ou ignoro a identidade do outro (seria o plano epistêmico); aqui não há, evidentemente, nenhum absoluto, mas uma gradação infinita entre os estados de conhecimento superiores e inferiores. (TODOROV, 2003, p. 269)

Dessa maneira, existe o interesse missionário de "assimilar o outro impondolhe a ele minha própria imagem", porém, apesar da limitação das fontes que foram produzidas a partir das notícias divulgadas por missionários batistas que desejavam atingir igrejas batistas brasileiras, é legítimo suspeitar que havia também, diversas limitações para esta assimilação que iam desde a influência cultural que os africanos exerciam na vida dos próprios missionários brasileiros e suas famílias até às escolhas realizadas por estes angolanos e moçambicanos que, por uma diversidade de razões a serem estudadas, preferiam, muitas vezes, se converter à religião trazida por estes missionários que também apresentavam reações variadas dentro dessa escala de possibilidades que se estabelecia entre o desconhecimento e o conhecimento do outro.

Para esse tipo de reflexão, é importante interrogar o silêncio das fontes para pensar, por exemplo, em que tipo de protestante se tornava o africano que anteriormente era um praticante das religiões tradicionais. Segundo o relato missionário, muitos destes, "apesar de crentes" continuavam "assombrados pelo paganismo" oque nos leva a supor que, em algum nível, esses novos protestantes continuavam, através de alguns elementos, praticando suas religiosidades ancestrais. Experimentando aquilo que Stuart Hall considera como uma zona de contato. Para este autor:

Através da transculturação "grupos subordinados ou marginais selecionam e inventam a partir dos materiais a eles transmitidos pela cultura metropolitana dominante". É um processo da "zona de contato", um termo que invoca "a co-presença espacial e temporal dos sujeitos anteriormente isolados por disjunturas geográficas e históricas (...) cujas trajetórias agora se cruzam". Essa perspectiva é dialógica, já que é tão interessada em como o colonizado produz o colonizador 
quanto vice-versa: a "co-presenca, interação, entrosamento das compreensões e práticas no interior de relações de poder radicalmente assimétricas". (HALL, 2002, p. 31)

Do ponto de vista dos missionários, apesar de estarem vivenciando a mesma zona de contato, nossas fontes apontam para a suspeita de que estes jamais saíam de si, pelo menos no momento de produção de um testemunho direcionado à sensibilização de seus “irmãos". Através destes relatos, é impossível notar a "colonização do colonizador", ou seja, a dialogicidade do contato. É mais visível a rejeição de um processo de interlocução que produziria, dialogicamente, um sentido para a África, na medida em que não interessa para a agência missionária as condições de produção ${ }^{7}, 0$ contexto histórico-social e os interlocutores.

Poderíamos afirmar que, diante da tarefa de significar o outro, os missionários, a partir de suas premissas e representações pré-construídas, resistiam aos africanos dentro do discurso de alteridade que construíam. As guerras e a convulsão política pelas quais passavam as colônias nem ao menos eram mencionadas, muito menos consideradas como um elemento essencial para a compreensão das posturas de aceitação e a boa receptividade do africano aos projetos de evangelização, receptividade esta que precisa ser compreendida dentro do campo discursivo do qual fazem parte essas fontes.

No mesmo depoimento sobre o cotidiano missionário em Angola, o pastor e obreiro Antônio Boorne afirma:

A coisa mais impressionante era a maneira tão amável com que os habitantes das espalhadas senzalas nos acolhiam durante nossas viagens missionárias. Aproximando-se de uma povoação, o motorista buzinava e ao chegarmos perto das casas, muita gente se aglomerava ao redor do carro. Era uma festa. Muitas vezes tinha que apertar a mão de meia dúzia de pessoas de uma só vez, todas sorridentes. A criançada, boquiaberta, incerta, não sabendo se fugia ou vinha mais pra perto ficava olhando. Pois muitas daquelas crianças, muitas já crescidas, até então nunca tinham visto um branco.

\footnotetext{
${ }^{7}$ Segundo Brandão, as condições de produção constituem a instância verbal de produção do discurso: o contexto histórico social, os interlocutores, o lugar de onde falam e a imagem que fazem de si, do outro e do referente. (BRANDÃO, 2011, p.105)
} 
A atenção que o povo dava era maravilhosa, jamais vi em qualquer outro lugar da Inglaterra, Portugal ou Brasil uma atenção assim. Era como se todos tivessem uma torturante sede e saboreavam com o coração toda e qualquer palavra da Bíblia que lhes chegava aos ouvidos. Para eles o evangelho se apresentava como as mais gloriosas "boas novas". Eis a atenção quase que hipnótica.”. (1966, nº. P.7).

Se, por um lado, é natural que, como pessoa religiosa, o missionário avalie a boa receptividade da missão como prova das necessidades espirituais daquele povo, por outro, ela não pode ser compreendida quando ignorado o contexto sócio-político do período de descolonização e a "torturante sede" a qual se referia, parecia ser de natureza exclusivamente espiritual. De qualquer modo, mesmo que a intensa instabilidade política e a aceleração dos conflitos entre os movimentos separatistas e a metrópole portuguesa não deixasse dúvidas sobre a essencialidade desse processo para a compreensão dos comportamentos culturais das pessoas da região, a revista prefere ignorá-los quase que inteiramente.

Tais constatações nos levariam a considerar duas atitudes: primeiramente a postura pragmática do missionário que faz uma leitura das culturas locais exclusivamente em função de sua missão ou meta. Para a Junta de Missões Mundiais e para as igrejas batistas brasileiras os africanos, naquele momento de convulsão política e social, estariam sedentos de uma verdade espiritual. Esta era uma premissa construída apriori e pela qual era resignificado qualquer comportamento cultural do povo africano.

Outra consideração que podemos discutir como consequência da constatação de que os africanos não funcionavam como interlocutores dentro do processo de elaboração do discurso missionário, diz respeito às reações dos moçambicanos e angolanos que, em grande número, aderiam à proposta religiosa batista. Esta opção exercida pelos africanos é central para pensar a tensão entre o colonialismo ocidental e o protagonismo dos sujeitos históricos que viviam na África.

Neste sentido, apesar de valorizarmos, desconfiamos das explicações que tendem a perceber a ação das agências missionárias, apenas, como pontas de lança do imperialismo europeu e estadunidense, ou da própria cultura ocidental, perspectiva que 
continua merecendo o reconhecimento de sua relevância, mas que carece da companhia de outros pontos de vista.

Portanto, seguindo nessa direção, pode-se destacar abordagens mais renovadoras de autores como Lamin Sanneh. Para este, o viés eurocêntrico (presente dentro da própria historiografia panafricana) e responsável por atribuir o protagonismo do crescimento cristão na África à atividade missionária, é insuficiente e falso. Em sua argumentação, as pessoas ouviram algo que "precisavam”. Nesse sentido, os maiores responsáveis pela propagação da mensagem cristã teriam sido os próprios africanos que multiplicavam o número de cristãos na África através das linhas de familiares e se, até o momento de escrita de seu livro na década de oitenta do século passado, a África era o continente mais cristão do mundo, isso não poderia ser explicado em razão dos estatisticamente poucos missionários cristãos ali atuantes (SANNEH, 1983).

No Brasil, esses estudos tem despertado a atenção de historiadoras como Silva (2011, p.7) que, a esse respeito, afirma:

Recentemente os paradigmas que associam missionarismo cristão ao colonialismo, ao imperialismo e à subordinação, estão sendo repensados por estudiosos como os historiadores africanos Lamin Sanneh e Ogbu Kalu. Para eles, nunca se levou em consideração como os africanos aceitaram ou rejeitaram os missionários e seus ensinamentos. Por exemplo, o fato de que chefes locais requisitaram a presença de escolas missionárias e clínicas médicas como um esforço contra seus inimigos e competidores políticos. Para estes autores, a ênfase nos paradigmas colonialistas acabou por silenciar os agentes locais e ignorar como a mensagem cristã foi traduzida de acordo com determinadas necessidades sociais e espirituais de cada grupo e cultura. (SILVA, 2011.p.7).

Os apontamentos da historiadora reverberam em outras passagens da Revista nas quais a missionária Valnice Milhomens, atuante em Moçambique, mencionava a experiência de um culto, no qual um ancião com 27 anos de conversão, fruto do trabalho escandinavo, "rogou-nos dizendo: Não nos abandonem, é de vocês que 
recebemos a luz de Cristo, existem milhões de africanos escravizados pelo pecado." (MILHOMENS, 1973, p. 8)

É notável que, segundo a missionária (e o fato de ser um testemunho desta pode fazer toda a diferença), as necessidades materiais e uma solução para os problemas do contexto político não tenham sido mencionadas pelo ancião que apelava pela continuidade do trabalho missionário na região, pois, segundo o próprio africano, a escravidão africana de então era provocada pelo pecado e não parecia relacionar-se com a historicidade das convulsões políticas, econômicas e sociais do período.

Dessa forma, notamos que estes africanos eram autores de suas histórias e realizavam suas próprias opções. O protagonismo dos angolanos e moçambicanos pode ser observado, ainda, em outros volumes da revista quando a mesma mencionava, já em 1974, a existência do Instituto Teológico de Moçambique, onde haveria "um bom número de alunos se preparando para servir ao Mestre"(ibdem, ibdi, p.24). Em edições de 1973, são fartas as páginas com textos e fotografias sobre Firmino Chife, jovem batista angolano que visitava o Brasil naquele ano e, no dia das missões estrangeiras, data especial marcada por diversas festividades nas comunidades batistas brasileiras, adquiria notoriedade e destaque assumindo a responsabilidade da pregação nas igrejas e convenções estaduais. (ibdem, ibdi,p.14)

Maria Olívia Felipe e Claudia Oliva de Melo, a primeira, angolana e a segunda moçambicana, também recebiam destaques na revista como resultados positivos do trabalho do casal de missionários Pastor Levy Barbosa da Silva e Elizabeth Barbosa da Silva. Ambas, em 1973, cursavam o segundo ano do curso de Educação Cristã no Brasil, a primeira no Rio de Janeiro e a segunda em Recife. No mesmo número, menciona-se o sexto congresso da Mocidade Batista de Moçambique com 96 inscritos (ibdem, 1973,p.33).

Este conjunto de acontecimentos está associado ao crescimento do cristianismo em solo africano ao longo do século XX. Período em que assistiu-se à forte redução das religiosidades tradicionais africanas. Afirma-se que, antes desse período, apenas $10 \%$ da África era cristã e que, atualmente, cerca da metade o é. Segundo o Centro de Estudos Africanos da Universidade do Porto, "O sucesso dessa expansão resultou fundamentalmente do facto de muitos dos africanos convertidos se terem transformado 
em missionários procedendo a uma readaptação cultural da mensagem." (CEAUP, $2011)^{8}$

\section{CONSIDERAÇÕES FINAIS}

O prosseguimento dessa pesquisa pretende pautar-se em uma discussão central: a verificação da ideia de que as mediações das distintas culturas representam, por um lado, elementos colonizadores e, por outro, fenômenos para além das colonizações culturais. Por isso, consideramos relevante continuar questionando sobre em que medida a presença de missionários brasileiros atuou como um elemento colonizador na África Lusófona e como pensar a reação dos africanos para além das resistências, uma vez que entre suas religiões tradicionais e o protestantismo batista parecia haver um modo próprio de reinventar-se e de assumir o protagonismo de suas construções identitárias dentro de um contexto específico de descolonização.

Dentro de um quadro de intensas transformações políticas e sociais, o texto ora proposto visou discutir as alteridades culturais no campo religioso a partir de apontamentos resultantes de preliminares investigações realizadas através da revista $O$ Campo é o Mundo da Junta de Missões Mundiais, organização pertencente à Convenção Batista Brasileira que, durante o período de descolonização da África lusófona, apresentava especial interesse na região.

Através do discurso desse periódico, pode-se perceber as construções de sentidos para a África Lusófona e o fato do discurso batista da revista revelar o não reconhecimento do africano enquanto interlocutor da construção de um sentido para a África não significa que esta realização não estivesse sendo elaborada pelos próprios angolanos ou moçambicanos que assumiam seus papeis de sujeitos históricos na medida em que faziam escolhas dentro do limitado elenco de opções que possuíam. Por isso, vale pensar nas afirmações de Eliane Moura:

As missões cristãs foram mais do que colonizações culturais: a mesma missão que converteu o Outro trouxe o Outro para dentro de si. As missões construíram novas culturas, nova hibridações e fronteiras de alteridades móveis em relações bastante complexas. (SILVA, 2011, p.6)

\footnotetext{
${ }^{8}$ (Disponível em: http://www.africanos.eu/ceaup/index.php?p=g\&n=346)
} 
Tais afirmações apontam para reflexões importantes. Fontes documentais menos condicionadas ao campo religioso protestante poderiam ampliar as percepções das hibridizações presentes nos contatos culturais experimentados por missionários e africanos. Essa ampliação documental é necessária uma vez que a seleção de informações construída pelo periódico analisado não parecia se interessar por ouvir os africanos no que diz respeito às suas culturas e seus saberes.

Essa primeira e provisória conclusão parece, de certa forma, contrastar com uma segunda: a de que os africanos não eram apenas alvo das missões e afirmavam seu protagonismo de diversas maneiras. Quando se convertiam ao protestantismo e continuavam manifestando antigas crenças e antigos hábitos culturais ou quando se tornavam, eles próprios, missionários em diáspora. Construindo, assim, novas relações culturais em processos que reinventavam as posições assimétricas separadas por antigos atlânticos.

\section{REFERÊNCIAS}

ALMEIDA, Vasni; SANTOS,Lyndon Araújo;SILVA,Elizete da. Fiel é a Palavra: Leituras Históricas dos Evangélicos Protestantes no Brasil. Feira de Santana, UEFS Editora, 2011.

BERGER, Peter. O Dossel Sagrado: Elementos para uma teoria sociológica da Religião. São Paulo, Paulos, 1985.

BRANDÃO, Helena Nagamine. Introdução à análise do discurso. Campinas, Unicamp, 2001.

CHARTIER, Roger. A História Cultural - entre Práticas e Representações. Rio de Janeiro. Bertran Brasil, 1990.

O mundo como representação. In: À beira da falésia: a história entre incertezas e inquietude. Trad. Patrícia Chittoni Ramos. Porto Alegre: Ed. Universidade/UFRGS, 2002. 
HALL, Stuart. Da Diáspora: Identidades e mediações culturais. Belo Horizonto, UFMG. 20013.

LOVEJOY, Paul. A escravidão na África: Uma história de suas transformações. Rio de Janeiro: Civilização Brasileira, 2002.

ORLANDI, Enni. Vão Surgindo os Sentidos. In: O Discurso Fundador: a formação do país e a construção da identidade nacional. 3ed. São Paulo: Pontes, 2003.

SANNEH, Lamin. West African Christianity: The Religious Impact. New York, Maryknoll: Orbis Books, 1983.

SILVA, Eliane Moura. Missionárias Protestantes AMERICANAS (1870 1920): GÊNERO, CULTURA, HISTÓRIA. Revista Brasileira de História das Religiões. ANPUH, Ano III, n. 9, Jan. 2011.

TSHIBANGU, T.; AJAYI, A. A. \& SANNEH, L. Religião e evolução social. In: MAZRUI, A. A. \& WONDJI, C. (Ed.). A África desde 1935. 2ª . ed. rev. Brasília: UNESCO, 2010.

TODOROV, Tzvetan. A conquista da América. São Paulo : s/ed. 1996.

VISENTINI, Paulo Gilberto Fagundes. Independência, Marginalização e Reafirmação da África (1957-2007). In MACEDO, José Rivair(org.) Desvendando a História da África. Porto Alegre, UFRGS. 2008.

\section{TEXTOS EM REVISTA IMPRESSA}

MILHOMENS, Valnice. Gritos e gemidos. O Campo é o Mundo, Rio de Janeiro, Julho a Setembro de 1971. p.7 e 8.

REDAÇÃO. E a África?O Campo é o Mundo, Abril a Junho de 1966, p. 4 e 5.

REDAÇÃO. Relação dos missionários. O Campo é o Mundo, Abril a Junho de 1974, p. 28. 


\section{NOTÍCIA NA INTERNET}

Colóquio Internacional - Da evangelização da África à África evangelizadora: Mediações missionárias em África e a partir de África - 17 e 18 de Outubro de 2013 FLUP. CEAUP - Centro de Estudos Africanos da Universidade do Porto. Disponível em <http://www.africanos.eu/ceaup/index.php?p=g\&n=346>. Acesso em 25 de Jun. de 2013. 